\title{
PSMB8 and PBK as potential gastric cancer subtype-specific biomarkers associated with prognosis
}

\author{
Chae Hwa Kwon ${ }^{1}$, Hye Ji Park ${ }^{1}$, Yu Ri Choi ${ }^{1}$, Ahrong Kim¹, Hye Won Kim ${ }^{1}$, Jin Hwa \\ Choi $^{1}$, Chung Su Hwang ${ }^{1}$, So Jung Lee ${ }^{1}$, Chang In Choi ${ }^{2}$, Tae Yong Jeon ${ }^{2}$, Dae Hwan \\ $\mathrm{Kim}^{2}$, Gwang Ha Kim ${ }^{3}$ and Do Youn Park ${ }^{1}$ \\ 1 Department of Pathology, Pusan National University Hospital and Pusan National University School of Medicine, and \\ BioMedical Research Institute, Pusan National University Hospital, Seo-Gu, Busan, Korea \\ ${ }^{2}$ Department of Surgery, Pusan National University Hospital and Pusan National University School of Medicine, and BioMedical \\ Research Institute, Pusan National University Hospital, Seo-Gu, Busan, Korea \\ ${ }^{3}$ Department of Internal Medicine, Pusan National University Hospital and Pusan National University School of Medicine, and \\ BioMedical Research Institute, Pusan National University Hospital, Seo-Gu, Busan, Korea
}

Correspondence to: Do Youn Park, email: pdy220@pusan.ac.kr

Keywords: stomach, adenocarcinoma, prognosis, PSMB8, PBK, gastric cancer

Received: August 10, 2015

Accepted: February 05, 2016

Published: February 15, 2016

\section{ABSTRACT}

Gastric adenocarcinoma is a common form of cancer associated with a poor prognosis. We analyzed microarray profiling data from 48 patients with gastric adenocarcinoma to characterize gastric cancer subtypes and identify biomarkers associated with prognosis. We identified two major subtypes of gastric adenocarcinoma differentially associated with overall survival $(P=0.025)$. Genes that were differentially expressed were identified using specific criteria $(P<0.001$ and $>\mathbf{1 . 5}$-fold); expression of 294 and 116 genes was enriched in good and poor prognosis subtypes, respectively. Genes related to translational elongation and cell cycle were upregulated in the poor prognosis group. Of these genes, upregulation of proteasome subunit beta type 8 PSMB8 and PDZ binding kinase PBK was confirmed by real-time reverse transcription-PCR analysis. PSMB8 or PBK knockdown had no effect on gastric cancer cell proliferation but suppressed cell migration and invasion, respectively. Furthermore, immunohistochemistry analysis of $\mathbf{3 8 5}$ gastric cancer patients revealed that increased nuclear expression of PSMB8 and PBK was correlated with depth of invasion, lymph node metastasis, and lower survival rates. Taken together, two gastric adenocarcinoma subtypes were predictive of prognosis. PSMB8 and PBK were predictive of gastric cancer prognosis and could be potential gastric cancer subtypespecific biomarkers.

\section{INTRODUCTION}

Gastric cancer is a common form of cancer with the second highest cancer-related mortality rate [1]. Advanced gastric cancer is generally refractory to chemotherapy, leading to a poor prognosis, with five-year survival rates of only $20-30 \%$ [2]. Even in patients at the early stage of the disease, the presence of lymph node metastasis considerably decreases survival rates [3]. Although the histological and pathological stages of gastric cancer have been the gold standard for determining prognosis, these only offer limited information about disease status in individual patients.

There is heterogeneity among tumors displaying a similar histopathological appearance, which results in different clinical outcomes. Thus, it is important to understand the molecular heterogeneity of tumors and to identify clinically useful biomarkers to identify gastric cancer patients with a poor prognosis for alternative treatment strategies. Biomarkers could advance the development of diagnostic or prognostic systems and anticancer drugs, while also providing more comprehensive information relating to mechanisms underlying tumorrelated processes. Previous studies have been focused on discovering novel biomarkers or gene signatures associated with gastric cancer using gene expression profiling [4, 5]. However, the subjective supervised methods used in these studies were suggested to result in 
bias relating to relevant processes, leading to classification that is not biologically meaningful [6]. Therefore, in the present study, we analyzed gene expression profiling data from 48 patients with gastric cancer and identified two subtypes that were clinically relevant in predicting prognosis based on their unique gene expression signatures using an unsupervised hierarchical clustering. In addition, we identified and validated two specific biomarkers associated with prognosis.

\section{RESULTS}

\section{Two subgroups of gastric cancer associated with prognosis}

An unsupervised hierarchical clustering analysis was performed to evaluate gene expression data obtained from 48 human gastric adenocarcinoma tissue samples (Supplementary Table 1). Genes with expression levels that displayed at least a two-fold difference in a minimum of ten tissue samples were selected for hierarchical clustering analysis (2,800 genes total). Unsupervised hierarchical clustering revealed two distinctive subtypes (Cluster $1(\mathrm{C} 1, \mathrm{n}=20)$ and Cluster $2(\mathrm{C} 2, \mathrm{n}=28))$ with clear differences in gene expression profiles (Figure 1A). Two subtypes did not correlate with level of tumor differentiation or histological type of tumor (data not shown). To further evaluate the association of these two subtypes with prognosis, we performed a Kaplan-Meier survival analysis. As shown in Figure 1B, C2 patients had a significantly lower overall survival rate compared with that of $\mathrm{C} 1$ patients $(P=0.02$, log-rank test). The average survival durations of the $\mathrm{C} 1$ and $\mathrm{C} 2$ subtypes were 24.7 and 23.7 months, respectively. These results suggest that the molecular signatures of these gastric tumors could be useful predictors of clinical outcomes.

\section{Gene expression signatures in gastric cancer associated with prognosis}

We next sought to identify genes that were differentially expressed between $\mathrm{C} 1$ and $\mathrm{C} 2$ subtypes by applying the following thresholds: $P<0.001$ and $>1.5$ fold change. We identified 294 and 116 genes displaying higher expression in $\mathrm{C} 1$ and $\mathrm{C} 2$ subtypes, respectively. We analyzed these gene lists using DAVID functional annotation tools to categorize the enriched genes into subtypes based on biological process (BP) and KEGG pathway (Figure 2 and Supplementary Table 2). Genes highly expressed in the $\mathrm{C} 1$ subtype were related to the following gene sets: GO_BP cell adhesion $(P=8.62$ $\left.\times 10^{-18}\right)$, cytoskeleton organization $\left(P=5.36 \times 10^{-6}\right)$, regulation of cell motion $\left(P=4.66 \times 10^{-6}\right)$, and vasculature development $\left(P=1.7510^{-5}\right)$; KEGG ECM-receptor interaction $\left(P=2.44 \times 10^{-9}\right)$, focal adhesion $(P=2.61 \times$ $\left.10^{-8}\right)$, and vascular smooth muscle contraction $(P=3.66$ $\left.\times 10^{-5}\right)$.

Genes more highly expressed in the $\mathrm{C} 2$ subtype were related to the following genes sets: $\mathrm{GO}$ BP translation $(P$ $\left.=5.64 \times 10^{-4}\right)$, RNA export from nucleus $\left(P=2.93 \times 10^{-}\right.$ $\left.{ }^{5}\right)$, negative regulation of ubiquitin-protein ligase activity during mitotic cell cycle $\left(P=2.84 \times 10^{-3}\right)$, cell cycle $(P=$ $\left.1.88 \times 10^{-2}\right)$, and KEGG ribosome $\left(P=2.13 \times 10^{-4}\right)$. Of the 116 genes highly expressed in the $\mathrm{C} 2$ subtype, 22 were associated with these GO terms and KEGG pathways, most of which are implicated in cancer: Ribosomal protein (RP)-encoding genes RPL6, RPLP0, RPL8, RPS6P1, PRS7, and RPL29 [9], eukaryotic translation elongation factor $E E F 1 B 2$ [10], eukaryotic translation initiation factor EIF5A [11], mRNA export factor THOC4 [12], heterogeneous nuclear ribonucleoprotein HNRNPA1 [13], mitotic arrest deficiency 2 MAD2 [14], proteasome subunits PSMA6 and PSMB8 [15], protein kinase regulatory subunit $C K S 2$ [16], and PDZ-binding kinase $P B K$ [17]. These results suggest that altered expression of these identified genes could reflect the specific molecular and biological features of gastric cancer cells.

\section{Validation of gene expression}

To validate the candidate genes that were highly expressed in C2 patient samples with poor prognosis, we performed a real-time PCR analysis using the same RNA used for the microarray analysis. The $\mathrm{C}_{\mathrm{T}}$ values for THOC4, PSMB8,CKS2 and PBK were significantly lower in $\mathrm{C} 2$ than $\mathrm{C} 1$, suggesting increased expression of these genes was associated with a poor prognosis (Supplementary Figure 1). These results are consistent with data from our microarray analysis.

We focused on PSMB 8 and $P B K$, whose functions in gastric cancer have not been reported. The Oncomine database (http://www.oncomine.org) was used to examine the differences in mRNA levels of PSMB 8 and $P B K$ between gastric cancer tissues and adjacent normal tissues. As shown in Supplementary Figure 2A and 2B, $P S M B 8$ and $P B K$ in microarray datasets (Cho et al. [18], and D'Errico et al. [19]) were overexpressed in gastric cancer tissues compared with that in normal tissues $(P=$ $0.006, P=0.007, P=0.001, P=4.34 \mathrm{E}-9)$. In addition, the protein levels of these molecules in gastric cancers were significantly higher than those in adjacent normal tissue, as shown in Supplementary Figure 2C and 2D.

\section{Roles of PSMB8 and PBK in gastric cancer cells}

To investigate the roles of $P S M B 8$ and $P B K$ in gastric cancer cells, SNU638 and AGS cells expressing high levels of these genes (Supplementary Figure 3), were transfected with siRNAs specific for each gene, 
Table 1: Relationship between nuclear PSMB8 expression and clinicopathological characteristics in 385 patients with gastric cancer

\begin{tabular}{|c|c|c|c|c|}
\hline & \multirow[b]{2}{*}{ [No.] } & \multicolumn{2}{|c|}{ Nuclear PSMB8 expression } & \multirow{2}{*}{$P$ value } \\
\hline & & $(-)(+)$ & $(++)$ & \\
\hline Age (years) & 385 & $59.6 \pm 0.66$ & $61.2 \pm 1.18$ & 0.224 \\
\hline Size $(\mathrm{cm})$ & 385 & $4.52 \pm 0.16$ & $5.65 \pm 0.38$ & 0.002 \\
\hline \multicolumn{5}{|l|}{ Sex } \\
\hline Male & 247 & $187(75.7)$ & $60(24.3)$ & \multirow{2}{*}{0.686} \\
\hline Female & 138 & $107(77.5)$ & $31(22.5)$ & \\
\hline \multicolumn{5}{|l|}{ Location } \\
\hline Upper & 43 & $30(69.8)$ & $13(30.2)$ & \multirow[t]{3}{*}{0.502} \\
\hline Middle & 126 & $99(78.6)$ & $27(21.4)$ & \\
\hline Lower & 216 & $165(76.4)$ & $51(23.6)$ & \\
\hline \multicolumn{4}{|l|}{ Gross typeq } & \multirow[t]{4}{*}{0.011} \\
\hline Elevated & 88 & $65(73.9)$ & $23(26.1)$ & \\
\hline Flat/Depressed & 143 & $121(84.6)$ & $22(15.4)$ & \\
\hline Excavated & 154 & $108(70.1)$ & $46(29.9)$ & \\
\hline \multicolumn{4}{|l|}{ Histological type* } & \multirow[t]{4}{*}{0.443} \\
\hline Intestinal & 219 & $164(74.9)$ & $55(25.1)$ & \\
\hline Diffuse & 162 & $127(78.4)$ & $35(21.6)$ & \\
\hline Mixed & 4 & $3(75.0)$ & $1(25.0)$ & \\
\hline \multicolumn{4}{|l|}{ Stage } & \multirow[t]{4}{*}{$<0.0001$} \\
\hline I & 196 & $166(84.7)$ & $30(15.3)$ & \\
\hline II & 74 & $57(77.0)$ & $17(23.0)$ & \\
\hline III & 115 & $71(61.7)$ & $44(38.3)$ & \\
\hline \multicolumn{4}{|l|}{ Invasion depth } & \multirow[t]{5}{*}{0.003} \\
\hline $\mathrm{T} 1$ & 181 & $150(82.9)$ & $31(17.1)$ & \\
\hline $\mathrm{T} 2$ & 59 & $48(81.4)$ & $11(18.6)$ & \\
\hline T3 & 62 & $43(69.4)$ & $19(30.6)$ & \\
\hline $\mathrm{T} 4$ & 83 & $53(63.9)$ & $30(36.1)$ & \\
\hline \multicolumn{4}{|l|}{ Perineural invasion } & \multirow{3}{*}{0.040} \\
\hline Negative & 226 & $181(80.1)$ & 45 (19.9) & \\
\hline Positive & 159 & $113(71.1)$ & $46(28.9)$ & \\
\hline \multicolumn{5}{|l|}{$\begin{array}{l}\text { Lymphovascular } \\
\text { emboli }\end{array}$} \\
\hline Negative & 236 & $196(83.1)$ & $40(16.9)$ & \multirow[t]{2}{*}{$<0.0001$} \\
\hline Positive & 149 & $98(65.8)$ & $51(34.2)$ & \\
\hline \multicolumn{4}{|l|}{$\begin{array}{l}\text { Lymph node } \\
\text { metastasis }^{\ddagger}\end{array}$} & \multirow[t]{5}{*}{$<0.0001$} \\
\hline N0 & 205 & $173(84.4)$ & $32(15.6)$ & \\
\hline N1 & 53 & $42(79.2)$ & $11(20.8)$ & \\
\hline $\mathrm{N} 2$ & 60 & $38(63.3)$ & $22(36.7)$ & \\
\hline N3 & 67 & $41(61.2)$ & $26(38.8)$ & \\
\hline
\end{tabular}

I between elevated+flat/depressed vs excavated, * intestinal + mixed vs diffuse 
Table 2: Relationship between nuclear PBK expression and clinicopathological characteristics in 385 patients with gastric cancer

\begin{tabular}{|c|c|c|c|c|}
\hline & \multirow[b]{2}{*}{ [No.] } & \multicolumn{2}{|c|}{ Nuclear PBK/TOPK expression } & \multirow{2}{*}{$P$ value } \\
\hline & & $(-)$ & $(+)(++)$ & \\
\hline Age (years) & 385 & $59.7 \pm 0.65$ & $60.8 \pm 1.20$ & 0.426 \\
\hline Size $(\mathrm{cm})$ & 385 & $4.58 \pm 0.17$ & $5.57 \pm 0.37$ & 0.010 \\
\hline \multicolumn{5}{|l|}{ Sex } \\
\hline $\begin{array}{l}\text { Male } \\
\text { Female }\end{array}$ & $\begin{array}{l}247 \\
138\end{array}$ & $\begin{array}{l}192(77.7) \\
114(82.6)\end{array}$ & $\begin{array}{l}55(22.3) \\
24(17.4)\end{array}$ & 0.256 \\
\hline \multicolumn{5}{|l|}{ Location } \\
\hline $\begin{array}{l}\text { Upper } \\
\text { Middle } \\
\text { Lower }\end{array}$ & $\begin{array}{r}43 \\
126 \\
216\end{array}$ & $\begin{array}{r}32(74.4) \\
98(77.8) \\
176(81.5)\end{array}$ & $\begin{array}{l}11(25.6) \\
28(22.2) \\
40(18.5)\end{array}$ & 0.489 \\
\hline $\begin{array}{l}\text { Gross type } \\
\text { Elevated } \\
\text { Flat/Depressed } \\
\text { Excavated }\end{array}$ & $\begin{array}{r}88 \\
143 \\
154\end{array}$ & $\begin{array}{r}72(80.7) \\
117(81.8) \\
118(76.6)\end{array}$ & $\begin{array}{l}27(19.3) \\
26(18.2) \\
36(23.4)\end{array}$ & 0.515 \\
\hline $\begin{array}{l}\text { Histological type* } \\
\text { Intestinal } \\
\text { Diffuse } \\
\text { Mixed }\end{array}$ & $\begin{array}{r}219 \\
162 \\
4\end{array}$ & $\begin{array}{r}179(81.7) \\
123(75.9) \\
4(100.0)\end{array}$ & $\begin{array}{c}40(18.3) \\
39(24.1) \\
0(0.0)\end{array}$ & 0.208 \\
\hline $\begin{array}{l}\text { Stage } \\
\text { I } \\
\text { II } \\
\text { III }\end{array}$ & $\begin{array}{r}196 \\
74 \\
115\end{array}$ & $\begin{array}{r}169(86.2) \\
57(77.0) \\
80(69.6)\end{array}$ & $\begin{array}{l}27(13.8) \\
17(23.0) \\
35(30.4)\end{array}$ & 0.002 \\
\hline $\begin{array}{l}\text { Invasion depth } \\
\text { T1 } \\
\text { T2 } \\
\text { T3 } \\
\text { T4 }\end{array}$ & $\begin{array}{r}181 \\
59 \\
62 \\
83\end{array}$ & $\begin{array}{r}153(84.5) \\
50(84.7) \\
44(71.0) \\
59(71.1)\end{array}$ & $\begin{array}{r}28(15.5) \\
9(15.3) \\
18(29.0) \\
24(28.9)\end{array}$ & 0.017 \\
\hline $\begin{array}{l}\text { Perineural invasion } \\
\text { Negative } \\
\text { Positive }\end{array}$ & $\begin{array}{l}226 \\
159\end{array}$ & $\begin{array}{l}186(82.3) \\
120(75.5)\end{array}$ & $\begin{array}{l}40(17.7) \\
39(24.5)\end{array}$ & 0.102 \\
\hline $\begin{array}{l}\text { Lymphovascular } \\
\text { emboli } \\
\text { Negative } \\
\text { Positive }\end{array}$ & $\begin{array}{l}236 \\
149\end{array}$ & $\begin{array}{r}195(82.6) \\
98(74.5)\end{array}$ & $\begin{array}{l}41(17.4) \\
51(25.5)\end{array}$ & 0.054 \\
\hline $\begin{array}{l}\text { Lymph node } \\
\text { metastasis } \neq\end{array}$ & & & & 0.010 \\
\hline $\begin{array}{l}\text { N0 } \\
\text { N1 } \\
\text { N2 } \\
\text { N3 }\end{array}$ & $\begin{array}{r}205 \\
53 \\
60 \\
67\end{array}$ & $\begin{array}{r}175(85.4) \\
40(75.5) \\
46(76.7) \\
45(67.2) \\
\end{array}$ & $\begin{array}{l}30(14.6) \\
13(24.5) \\
14(23.3) \\
22(32.8)\end{array}$ & \\
\hline
\end{tabular}

* intestinal+mixed vs diffuse 

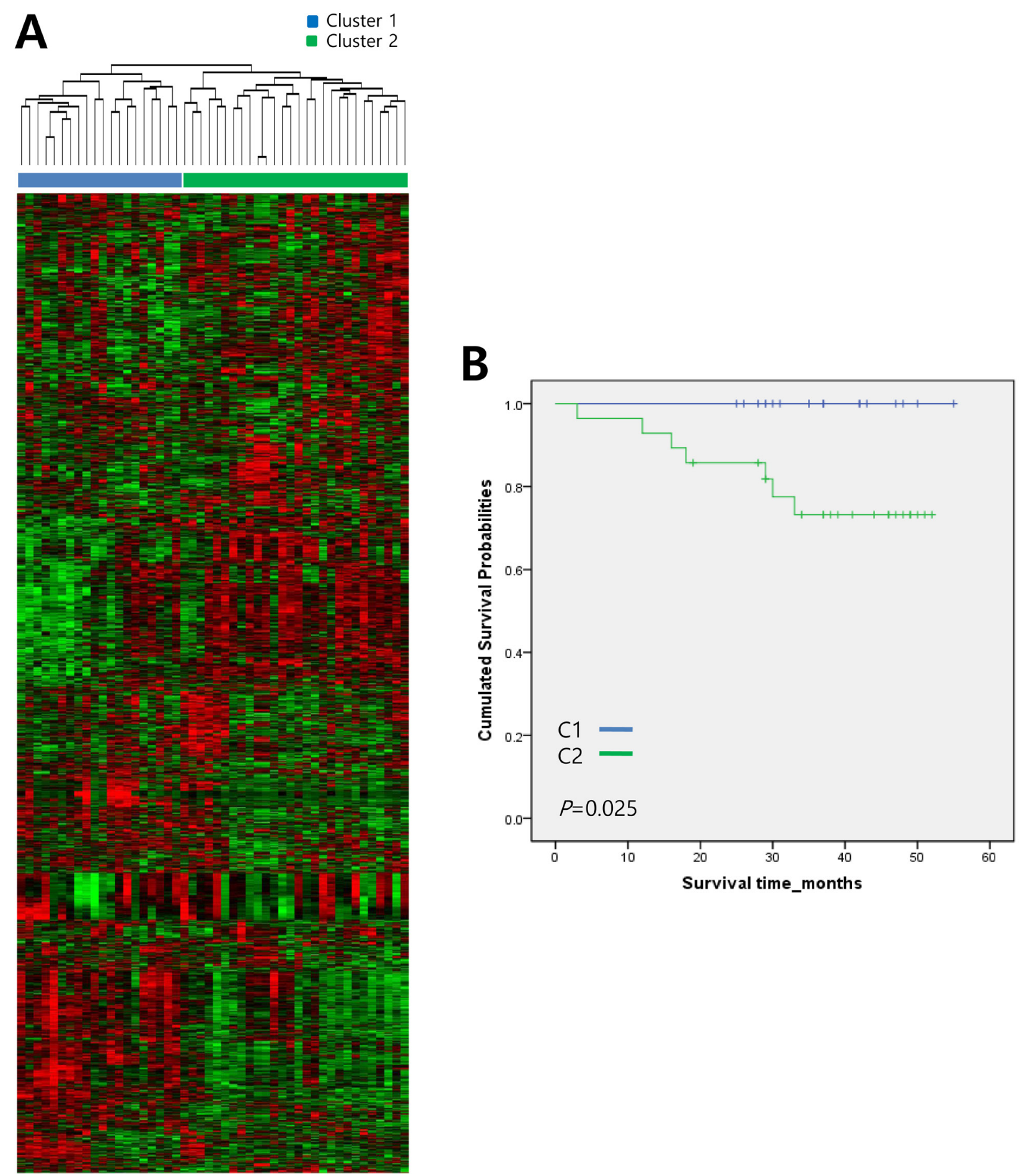

Figure 1: Hierarchical clustering analysis of gene expression data from 48 human gastric adenocarcinoma tissue samples. A. Genes with expression levels that were at least two-fold different in at least ten tissue samples were selected for unsupervised hierarchical clustering analysis (2,800 gene features). The results show two distinctive subtypes with significant differences in their respective gene expression signatures. Data are presented in a matrix format, in which each row represents an individual gene and each column represents a different tissue sample. Each cell in the matrix represents the expression level of a gene feature in an individual tissue sample. Red, high expression; green, low expression. B. Kaplan-Meier survival curves of the two clusters based on gene expression signature. $P$-values were obtained using the log-rank test. 
and proliferation, migration, and invasion assays were performed. Gene knockdown was verified using realtime PCR, western blotting, and immunocytochemistry (Figure 3A-3C). Knockdown of either PSMB 8 or $P B K$ had no effect on gastric cancer cell proliferation (Figure 3D). However, knockdown of each gene significantly decreased gastric cancer cell migration and invasion (Figure 4A-4D), suggesting that PSMB8 and PBK are involved in gastric cancer progression.

\section{Clinical relevance of PSMB8 and PBK expression in gastric cancer cells}

We next performed immunohistochemistry staining to detect PSMB8 and PBK protein expression in 385 gastric cancer specimens that were not the same as those used in the microarray studies. PSMB8 expression was identified in the cytoplasm and nuclei of gastric adenocarcinoma cells (Figure 5A). Regarding nuclear
PSMB8 expression, positive staining at levels of either $<5 \%(-)$ or $5-25 \%(+)$, and $>25 \%(++)$ was observed in $62.3 \%$ (249 of 385) and $23.6 \%$ (91 of 385) of cases, respectively. Regarding cytoplasmic PSMB8 expression, - $(240 / 385,62.3 \%),+(104 / 285,27.0 \%)$, and $++(41 / 385$, $10.6 \%$ ) were observed in gastric adenocarcinoma cells.

We investigated the clinicopathological and prognostic significance of nuclear PSMB8 expression in 385 cases of gastric adenocarcinoma (Table 1). Nuclear PSMB8 expression was associated with increased invasiveness of gastric adenocarcinoma, including higher stage $(P<0.0001)$, depth of invasion $(P=0.003)$, lymph node metastasis $(P<0.0001)$, lymphovascular tumor emboli $(P<0.0001)$, increased tumor size $(P=0.002)$, and perineural invasion of tumor cells $(P=0.040)$. However, no significant differences in nuclear PSMB8 expression were associated with patient sex, age, or location. Consistent with the association between nuclear PSMB8 expression and gastric adenocarcinoma aggressiveness, the patient group survival rate decreased as nuclear PSMB8
C1

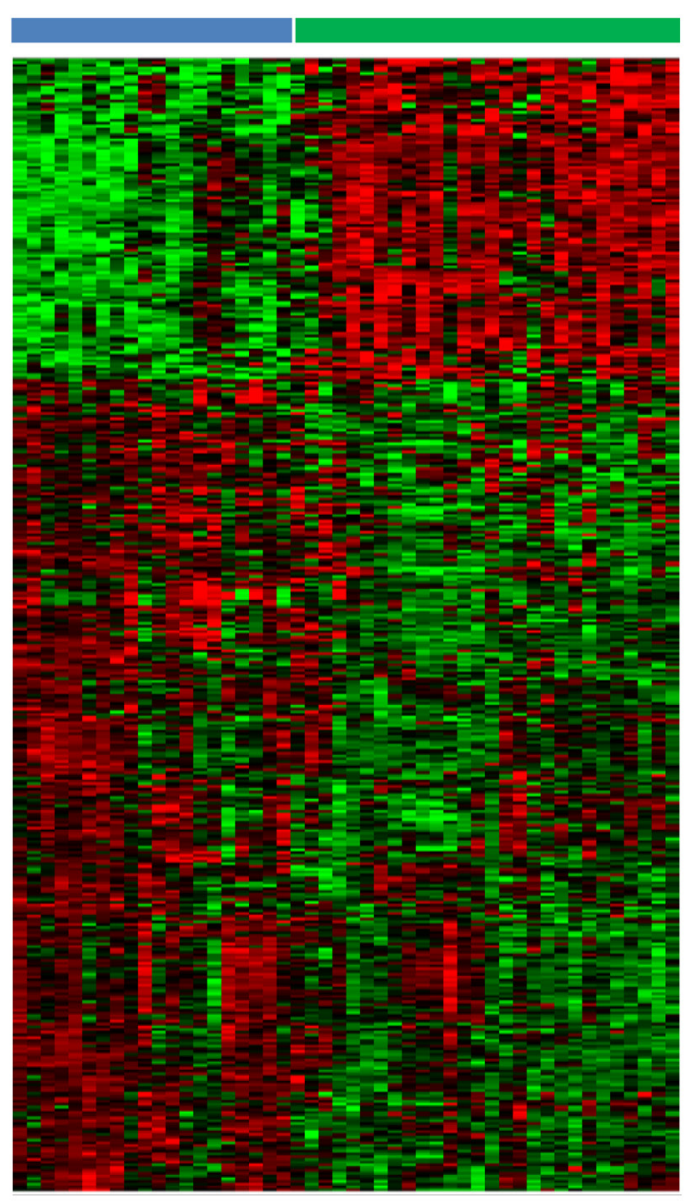

GO_Biological Process KEGG

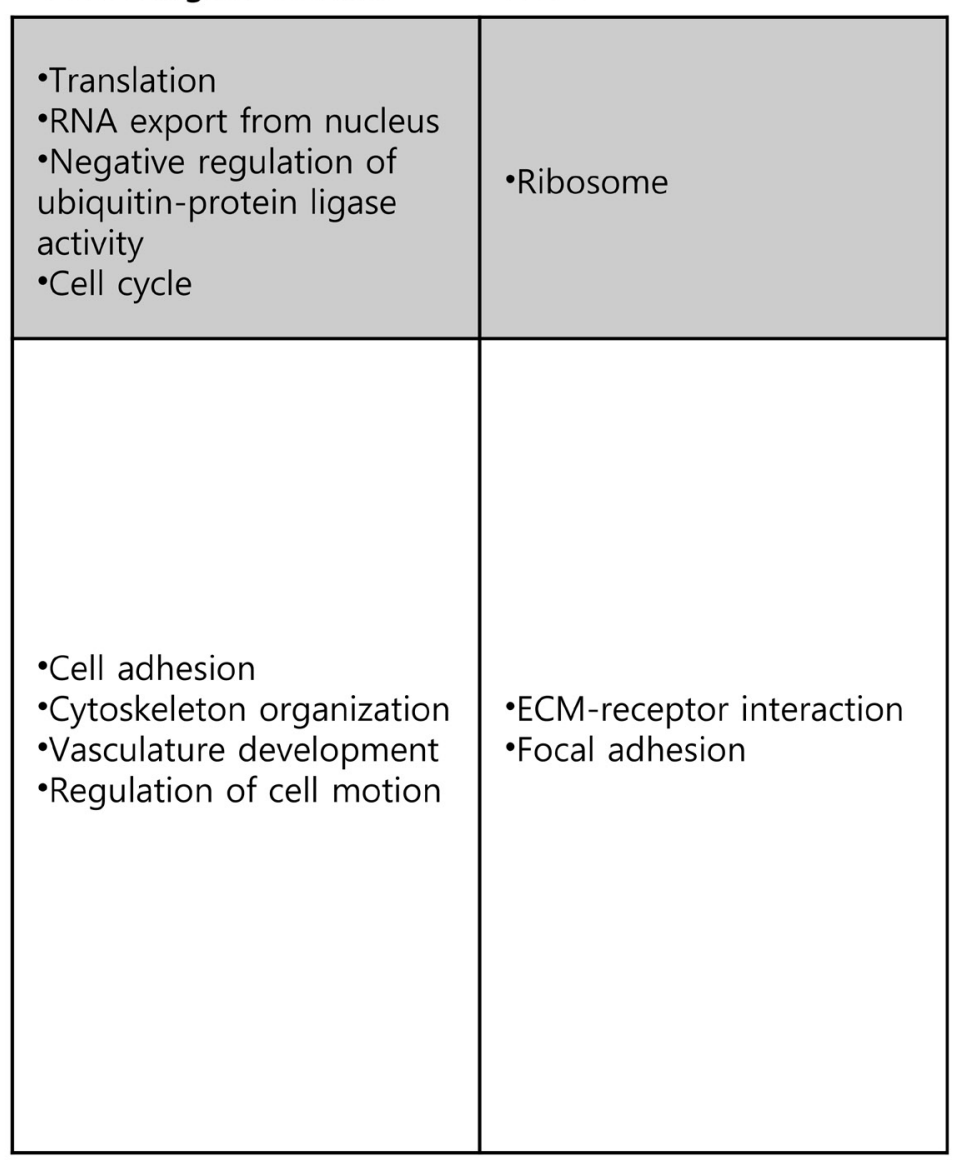

Figure 2: Subtype-specific gene signature and annotation. Two-sample $t$-tests were applied to gene expression data from the two subtypes and differences were considered statistically significant if $P<0.001$ and $>1.5$ fold change. Differentially expressed genes were categorized based on biological processing and KEGG pathway. Red, high expression; green, low expression. 

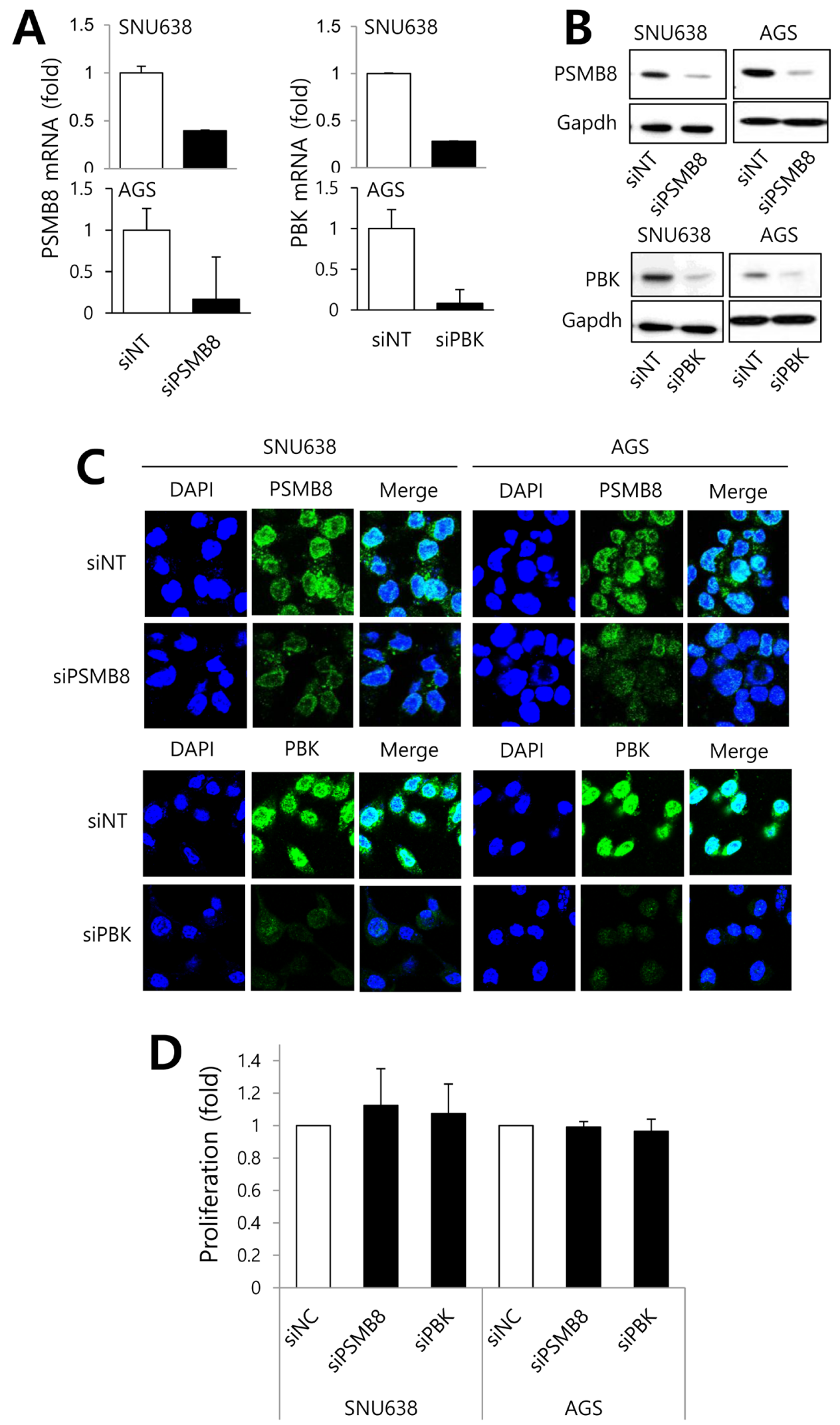

Figure 3: The roles of PSMB8 and PBK in proliferation of gastric cancer. SNU638 and AGS cells were transfected with either non-targeting siRNA (siNT), $P S M B 8$ siRNA (siPSMB8), or $P B K$ siRNA (siPBK) for 48 hours. PSMB8 and PBK mRNA and protein expression was determined using real-time PCR A., western blotting B., and immunocytochemical analysis C. D. After transfection, proliferation was evaluated using an MTT assay. 


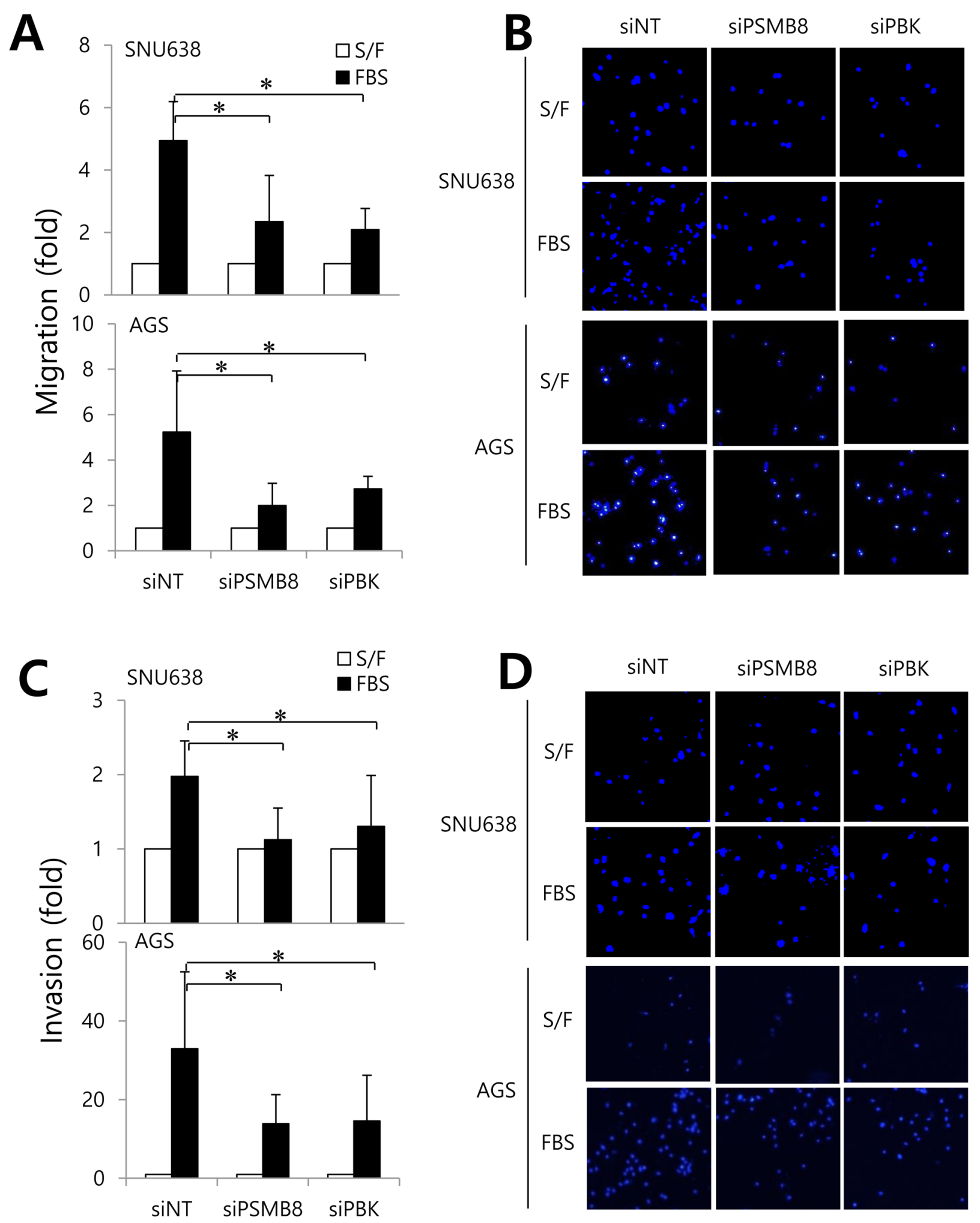

Figure 4: The roles of PSMB8 and PBK in migration and invasion of gastric cancer. SNU638 and AGS cells were transfected with either non-targeting siRNA (siNT), $P S M B 8$ siRNA (siPSMB8), or $P B K$ siRNA (siPBK) for 48 hours. The migration and invasion assays were subsequently performed. Graphs and representative data show cells that migrated $\mathbf{A}$. and $\mathbf{B}$. and invaded (C and D) in the presence (S/F, serum free) or absence of $1 \%(\mathrm{FBS}) . * P<0.05$. 
expression increased (Figure 5C). The average survival durations of the $(-),(+)$, and $(++)$ groups, which were classified according to nuclear PSMB8 expression, were 77.2, 70.6, and 62.2 months, respectively; this decrease was statistically significant $(P=0.004)$. However, cytoplasmic PSMB8 expression was not associated with clinicopathological variables or poor outcomes (data not shown).

PBK expression was identified in cytoplasm and nuclei of gastric adenocarcinoma cells (Figure 5B). Nuclear/cytoplasmic PBK expression in gastric adenocarcinoma tumor cells was classified as follows: - $(306 / 385,79.5 \%),+(67 / 385,17.40 \%)$, and ++ cytoplasmic expression $(12 / 385,3.1 \%)$; $-(234 / 385$,

\section{A}
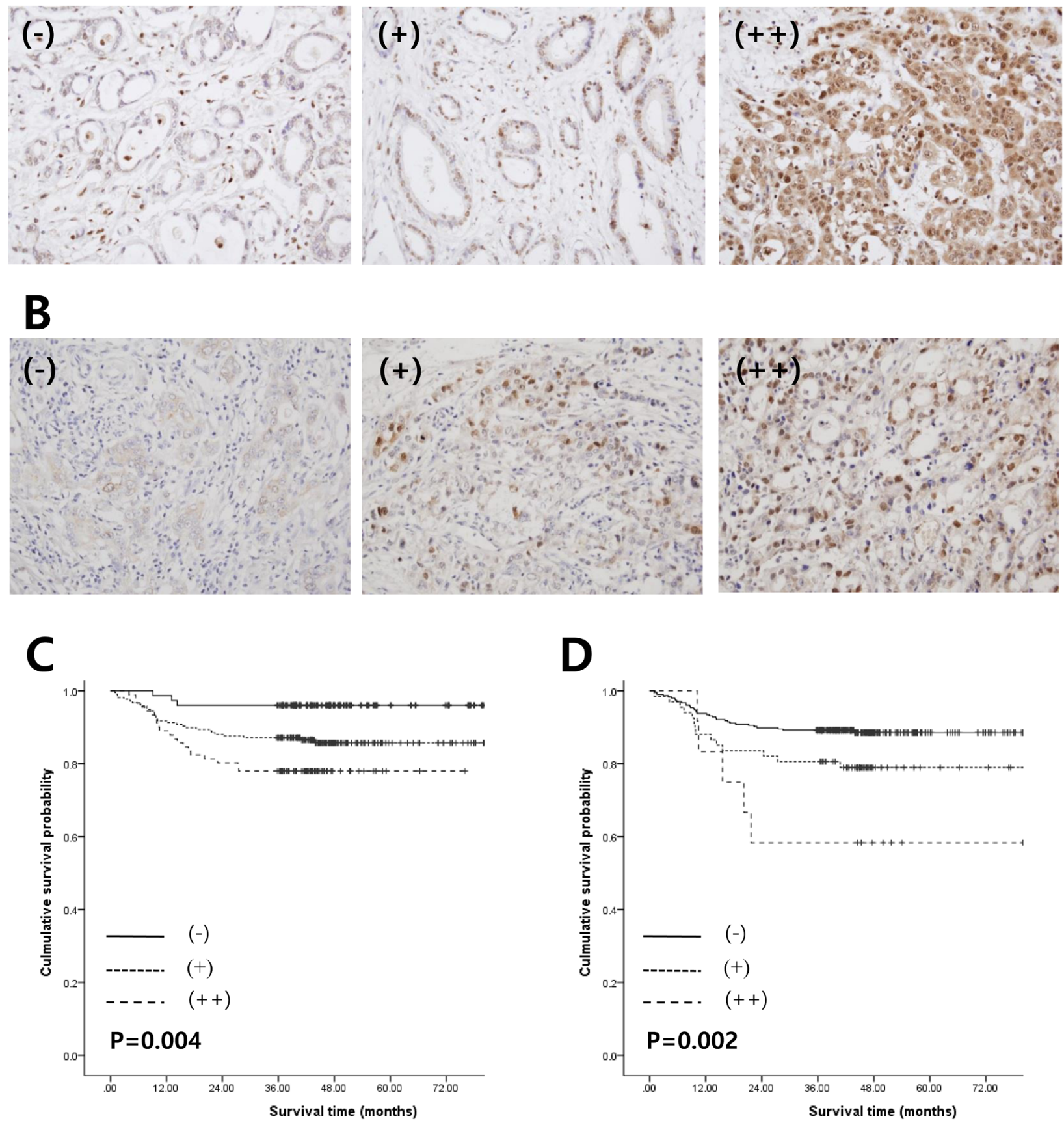

Figure 5: Relationship between expression of PSMB8 or PBK and clinical outcomes in patients with gastric cancer. A. and B. PSMB8 and PBK protein expression levels were determined by immunohistochemistry analysis. $(-),(+)$ or $(++)$ nuclear staining for PSMB8 or PBK was observed in tumor cells. C. and D. Kaplan-Meier survival analysis was performed according to PSMB8 or PBK expression. $P$-values were calculated using the log-rank test. 
$60.8 \%),+(117 / 285,30.4 \%)$, and ++ nuclear expression $(34 / 385,8.8 \%)$. Nuclear PBK expression was associated with increased gastric adenocarcinoma invasiveness, including higher stage $(P=0.002)$, depth of invasion $(P$ $=0.017)$, and lymph node metastasis $(P=0.001)$, similar to the PSMB nuclear expression results. However, no significant differences in nuclear PSMB8 expression status were associated with patient sex, age, location, perineural invasion, or lymphovascular tumor emboli (Table 2). Increased nuclear PBK expression was associated with a poor prognosis in gastric adenocarcinoma ((-), $72.3 \pm 1.2$; $(+), 66.2 \pm 3.4 ;(++), 53.1 \pm 9.2 ; P=0.002)$ (Figure 5D). However, cytoplasmic PBK expression was not associated with increased gastric adenocarcinoma invasiveness or poor outcomes (data not shown).

In addition, multivariate analysis showed that nuclear expression of PSMB8 and PBK were borderline significant predictors of overall survival $(P=0.085, P$ $=0.083$, respectively) (Supplementary Table 3 and 4 ). These findings indicate that nuclear PSMB8 and PBK overexpression in tumor cells correlates with gastric cancer progression, especially aspects relating to tumor invasion depth and lymph node metastasis. These genes could be candidate biomarkers for prediction of gastric cancer survival.

\section{DISCUSSION}

We performed microarray-based profiling to identify subtypes of gastric adenocarcinoma with different gene expression signatures. Using an unsupervised clustering approach, we found that gastric cancer patients were divided into two distinct subtypes that significantly differed with respect to overall survival, underscoring the clinical relevance of these subtypes. In addition, we identified 410 genes that could predict the prognosis of gastric cancer patients. Of these 410 genes, 294 were related to cell adhesion and ECM and were highly expressed in the subtype with a good prognosis. Previous studies have reported that inhibition of collagen fibril formation increases tumor cell invasion and ECM accumulation, contributing to tumor cell necrosis [20, 21]. These findings indicate that ECM constituents inhibit tumor progression, resulting in a good prognosis. Of 410 genes, 116 were highly expressed in the subtype with a poor prognosis. The biological functions of these 116 genes were associated with cancer and included translation, RNA transport, cell cycle, and the ribosome pathway.

Consistent with our results, a previous study identified ribosomal proteins as prognostic markers for gastric cancer [6]. Dysregulation of ribosome synthesis promotes tumor formation [22]. Ribosome synthesis and protein translation are closely coordinated processes [23]. Translation elongation factor $E E F 1 B 2$ and translation initiation factor EIF5A have non-canonical functions unrelated to protein synthesis [24], which are reported to control cancer cell proliferation $[10,25]$. Prior to translation, mRNA is processed, edited, and exported. We found that THOC4 and HNRNPA1, which are associated with mRNA processing, were overexpressed in the $\mathrm{C} 2$ subtype with a shorter survival period. These genes have been reported to display altered expression in various forms of cancer, with higher expression associated with cancer development $[12,13,26,27]$.

Genes related to the cell cycle were also identified as upregulated in tissue from patients with a poor prognosis. $M A D 2$ and $B U B 3$ are involved in spindle checkpoint function, with increased $M A D 2$ expression associated with the formation of aggressive tumors in multiple organs [14]. $P B K$ is a serine/threonine protein kinase related to the mitogen-activated protein kinase kinase (MAPKK) family. Overexpression of this gene has been implicated in tumorigenesis $[17,28]$. Moreover, the cyclin kinase subunit $C K S 2$ was upregulated; $C K S 2$ expression was increased in several types of cancer and associated with tumor progression [29, 30]. Tumor cells proliferate rapidly and have high rates of protein synthesis, consequently displaying higher proteasome activity $[31,32]$. Consistent with this, proteasome subunit PSMA6 and PSMB8 were more highly expressed in gastric cancer patients with a poor prognosis compared with patients with a good prognosis.

Because the C2 subtype was highly associated with a poor prognosis, we validated genes that were highly expressed in the $\mathrm{C} 2$ subtype using real-time PCR. THOC4, $P S M B 8, C K S 2$, and $P B K$ were validated. Of these genes, we focused on $P S M B 8$ and $P B K$. The proteasome system is a non-lysosomal proteolytic pathway with important roles in many cellular processes, such as cell cycle regulation, proliferation, differentiation, and inflammation [33]. Other proteasome subunits have been shown to be overexpressed in some tumor cell types $[34,35]$. However, the role of $P S M B 8$, a component of the 20 S proteolytic core particle of the proteasome, has not been reported in cancer. Although $P B K$ is also involved in many cellular functions, including tumor development, cell growth and cell death, and is highly expressed in many cancers [36-39], its role in gastric cancer has not been reported. Thus, we investigated the functional role of these genes on gastric cancer using siRNAs against each gene. Knockdown of PSMB 8 and $P B K$ decreased gastric cancer cell migration and invasion, respectively.

We next performed an immunohistochemistry analysis of 385 gastric cancer patients to evaluate the relationship between expression of PSMB8 or PBK and clinicopathological characteristics. Strong nuclear expression of PSMB8 and PBK significantly correlated with increased depth of invasion and lymph node metastasis, respectively. Elevated nuclear expression of PSMB8 was related to lymphovascular tumor emboli, increased tumor size, and perineural invasion of tumor 
cells. Consistent with our microarray results, a KaplanMeier survival analysis revealed that gastric cancer patients displaying high protein expression of either PSMB8 or PBK had a decreased survival rate. These results indicate that PSMB8 and PBK promote carcinogenesis and gastric cancer metastasis, and are potential biomarkers able to predict a poor prognosis. In addition, PSMB8 and PBK are useful immunohistochemical protein markers for potential surgical pathology application, as prediction of lymph node metastasis based on biopsy specimen evaluation prior to endoscopic resection is a critical decision point. Other studies described gene signatures associated with gastric cancer prognosis. These approaches cannot be easily translated into the clinic due to of the difficulty of acquiring fresh-frozen tissues from patients and the complexity of data analysis [18]. To our knowledge, this is the first report to characterize the roles of PSMB8 and $\mathrm{PBK}$ in gastric cancer progression.

Although we clearly suggested that PSMB8 and PBK promote the migration and invasion of gastric cancer cells, PSMB8 and PBK are not sufficient to proliferation by themselves in gastric cancer cells. Additional factor might be required to cooperate in inducing proliferative effect of PSMB8 or PBK. The molecular mechanism by which PSMB8 and PBK promote gastric cancer cell progression has not been elucidated. Although it has been reported that carcinoma cell motility and invasiveness occur via the PI3K [40] and MAP kinase pathways [41], we observed unaltered activation of Akt, ERK, or p38 following PSMB8 or PBK downregulation in gastric cancer (Supplementary Figure 4). These findings suggest that activation of the PI3K or MAPK pathways was not involved in PSMB8 or PBK-induced cell motility and invasiveness. Proteasome subunit has been reported to regulate transcription factors by nuclear localization and promoter interaction [42]. Another subunit, PSMB1, resides in the nucleus and binds to the PAI-2 and Reg1 promoters to upregulate expression of target genes related to tumor progression [43]. PBK is also localized to nuclei, where it is involved in phosphorylation of histone $\mathrm{H} 3$ and inhibition of p53 in colorectal cancer and breast cancer cells, respectively $[37,44]$. In addition, PBK is reported to correlate with mutant p53 and affects cell proliferation and viability in lung adenocarcinoma [45]. In future studies, we will investigate the underlying mechanisms of PSMB8 and PBK in detail.

In conclusion, we identified the expression signatures of two distinct subtypes of gastric cancer associated with different survival rates. Further validation of these gene signatures will be necessary in a larger cohort of patients. We propose that PSMB8 and PBK could be useful biomarkers for identifying gastric cancer patients with a poor prognosis. These findings could contribute to developing an improved method of molecular classification of gastric cancer patients that can predict survival. These markers also have the potential for clinical application, including the development of diagnostic markers and therapeutic agents for gastric cancer.

\section{MATERIALS AND METHODS}

\section{Patients and samples}

As we described in our previous study [7], a total of 48 fresh gastric cancer tissues were obtained with informed consent from patients who underwent gastrectomy at Pusan National University Hospital (PNUH) and Cheon Nam National University Hospital (CNUH), members of the National Biobank of Korea, which is supported by the Ministry of Health, Welfare, and Family Affairs, and were analyzed by microarray. Clinical characteristics of the patients were shown in Supplementary Table 1.

\section{Gene expression data and analysis}

Total RNA was extracted from 48 fresh-frozen tissues using a mirVana RNA Isolation kit (Ambion Inc., Austin, TX). Five-hundred nanograms of total RNA was used for cDNA synthesis, which was followed by an amplification/labeling step (in vitro transcription) using the Illumina TotalPrep RNA Amplification kit (Ambion). Labeled, amplified material (1500 ng per array) was hybridized to Illumina HumanHT-12 BeadChips v4.0, according to the manufacturer's instructions (Illumina, San Diego, CA). Array signals were developed by streptavidinCy3. Arrays were scanned with an Illumina iScan system. The microarray data were normalized using the quantile normalization method in Illumina BeadStudio software. Microarray data are available in NCBI's GEO (Gene Expression Omnibus) database (http://www.ncbi.nlm.nih. gov/geo/query/acc.cgi?acc=GSE38024).

The expression level of each gene was transformed into a $\log ^{2}$ base before further analysis. Excel was primarily used for the statistical analyses. Gene expression differences were considered statistically significant if the $P$ value was $<0.001$ and all tests were 2-tailed. Cluster analyses were performed using Cluster and Treeview. The gene ontology (GO) program (http://david.abcc.ncifcrf. gov/) was used to categorize genes into subtypes based on biological function and pathway. Fisher's exact test was used to determine whether the proportions of genes in each category differed by group. Prognostic significance was estimated by Kaplan-Meier plots and log-rank tests between two predicted subtypes of patients. This statistical calculation was performed with SPSS version 10.0 for Windows (SPSS Inc., Chicago, IL, USA). 


\section{Real-time PCR}

Total RNA was extracted from gastric cancer cells, using the TRIzol reagent (Invitrogen), following the manufacturer's instructions. RNA was reverse transcribed with SuperScript II (Invitrogen) and cDNA was amplified with each primer and visualized with SYBR Green (Applied Biosystems; Life Technologies; NY, USA), using the fluorescence reader Corbett Rotor-Gene 6000 (Qiagen Inc., CA, USA). The primers used are the following:: glyceraldehyde 3-phosphate dehydrogenase (GAPDH), 5'-TCCATGACAACTTTGGTATCG-3', 5'-TGTAGCCAAATTCGTTGTCA-3'; PSMB8, 5'-GCTGCCTTCAACATAACATCA-3',

5'-CTGCCACCACCACCATTA-5'; CKS2, 5'-TAA GGCAACTGGTAAGCATTC-3', 5'-ACAAGATACAGCCAAGTGTTAGTCC-3'; PBK, 5'- GCCAGCCAAGATCCTTTTCC-3', 5'TCTGTGACGTGACAAGCTGA-5'; THOC4, 5'- TTTGGAACGCTGAAGAAGGC-3', 5'TCTGTGACGTGACAAGCTGA-3' The following thermal cycler program was used: denaturation for 30 $\mathrm{s}$ at $95^{\circ} \mathrm{C}$; annealing for $30 \mathrm{~s}$ at $52^{\circ} \mathrm{C}$, depending on the primers used; and extension for $30 \mathrm{~s}$ at $72^{\circ} \mathrm{C}$. The number of PCR cycles was determined for each gene and ranged from 25 to 35. Data were normalized to GAPDH, and mRNA abundance was calculated using the $2^{-\triangle \Delta C T}$ method.

\section{Cell lines and transfection}

The human gastric cancer cell lines SNU638 was obtained from the Korean Cell Line Bank (Seoul, South Korea) and were authenticated. These cells were cultured in RPMI1640 medium with $10 \%$ fetal bovine serum (FBS; GIBCO; Thermo Scientific Inc.; PA, USA), $100 \mathrm{U} / \mathrm{mL}$ penicillin, and $100 \mu \mathrm{g} / \mathrm{mL}$ streptomycin (Sigma-Aldrich; MO, USA). All cells were maintained at $37^{\circ} \mathrm{C}$ in $5 \% \mathrm{CO}_{2}$. For knockdown of genes, cells were transfected with PSMB8 or PBK smartpool short interfering RNA (siRNA) or with non-targeting siRNA as a control (Dharmacon; Thermo Scientific Inc.; PA, USA), using Lipofectamine RNAiMAX reagent (Invitrogen) according to the manufacturer's instructions. The siRNA sequences were as follows: PSMB8 (5696) siRNA, 5'-UGAUUGAGAUUAACCCUUA-3', 5'-UCAGCUGGGUCCUACAUUA-3', 5'-GGCUAUCGGCCUAAUCUUA-3', 5'-GAGAACGUAUUUCAGUGUC-3'; PBK (55872) siRNA, 5'-CAAGACACCAAGCAAAUUA-3', 5'-GGCAAGAGGGUUAAAGUAU-3', 5'-GUUCAACUCCAACUAUAAA-3', 5'-GAUCAUUAUCGAAGUGUGU-3'.

\section{Cell proliferation}

Cell proliferation was evaluated using MTT assay. Cells were transfected with siRNA for 48 hours and then washed. Culture medium containing $0.5 \mathrm{mg} / \mathrm{ml}$ of MTT was added to each well. The cells were incubated for $3 \mathrm{~h}$ at $37{ }^{\circ} \mathrm{C}$, the supernatant was removed and the formed formazan crystals in viable cells were solubilized with dimethyl sulfoxide. A $0.1 \mathrm{ml}$ aliquot of each sample was then translated to 96-well plates and the absorbance of each well was measured at $550 \mathrm{~nm}$ with spectrophotometer.

\section{Immunocytochemistry}

Cells were cultured on glass coverslips and transfected with siRNA. Cells were washed twice with PBS, fixed with 4\% paraformadehyde in PBS for $10 \mathrm{~min}$, permeabilized with $0.5 \%$ Triton X-100 in PBS for 10 min. After washing twice with PBS, cells were blocked with $8 \%$ BSA in Tris-buffered saline Triton X-100 (TBST). Cells were incubated with anti-PSMB8 or anti-PBK overnight $4{ }^{\circ} \mathrm{C}$ and washed twice with TBST. Cells were incubated with FITC-conjugated secondary antibody (Jackson ImmunoResearch Laboratories, PA, USA) for $1 \mathrm{~h}$, and the nuclei were counterstained with DAPI to determine nuclear localization. Coverslips were mounted and visualized by using the confocal microscope.

\section{Cell migration and invasion assays}

Gastric cancer cells were harvested with $0.05 \%$ trypsin containing $0.02 \%$ EDTA (Sigma-Aldrich) and suspended in RPMI medium. For the migration assay, membrane filters (8- $\mu \mathrm{m}$ pore size) in disposable 96 -well chemotaxis chambers (Neuro Probe; Gaithersburg, MD, USA) were pre-coated with $5 \mathrm{mg} / \mathrm{mL}$ fibronectin for $4 \mathrm{~h}$ at room temperature. Cells $\left(3 \times 10^{3}\right.$ cells/well $)$ were loaded into the upper chambers, and $1 \%$ FBS was loaded into the lower chamber. After $24 \mathrm{~h}$ of incubation, non-migrating cells were removed from the upper chamber with a cotton swab, and the cells on the lower surface of the insert were stained with Hoechst33342 (Sigma-Aldrich). Migrated cells were counted under a fluorescence microscope at $10 \times$ magnification.

For the invasion assay, $3 \times 10^{4}$ cells/well were seeded in the upper chamber, which was coated with $30 \mu \mathrm{L}$ of Matrigel $(1 \mathrm{mg} / \mathrm{mL}$ in cold medium; BD Transduction Laboratories; NJ, USA). Serum-free medium containing $1 \%$ FBS or control vehicle was added to the lower chamber. After $24 \mathrm{~h}$ of incubation, non-invading cells were removed from the upper chamber with a cotton swab, and cells on the lower surface of the insert were stained with Hoechst33342 (Sigma-Aldrich). Invasive 
cells were counted under a fluorescence microscope at $10 \times$ magnification.

\section{Western blot analysis}

Cells were harvested and disrupted in lysis buffer (1\% Triton X-100, 1 mM EGTA, 1 mM EDTA, 10 mM Tris- $\mathrm{HCl}$ at $\mathrm{pH} 7.4$, and protease inhibitors). Cell debris was removed via centrifugation at $10,000 \times g$ for $10 \mathrm{~min}$ at $4^{\circ} \mathrm{C}$. The resulting supernatants were resolved using SDSPAGE and transferred onto nitrocellulose membranes. The membranes were blocked with 5\% non-fat dried milk at room temperature for $30 \mathrm{~min}$ and incubated with anti-PSMB8 (Abcam; MA, USA), anti-PBK, anti-Akt, anti-ERK, anti-p38 (Cell Signaling Technology; MA, USA), and anti-GAPDH. The membranes were then washed and incubated with horseradish peroxidaseconjugated secondary antibody. Signals were visualized using enhanced chemiluminescence (Amersham; Buckinghamshire, UK).

\section{Immunohistochemistry and analysis of clinicopathological and prognostic significance}

We studied a cohort of 385 gastric cancer patients who underwent gastrectomy with lymph node dissection at PNUH between 2005 and 2007. None of the patients received preoperative radiotherapy or chemotherapy. Standard formalin-fixed and paraffin-embedded sections were obtained from the Department of Pathology and the National Biobank of Korea, PNUH. All samples from the National Biobank of Korea were obtained with informed consent under institutional review board-approved protocols.

Methods of immunohistochemistry have previously been described [8]. The percentage of positive cells showing moderate to strong staining intensity was scored. The score is explained as follows: $(-),<5 \%$; (+), 5\%$25 \%$; $(++),>25 \%$. Clinicopathological features were analyzed for differences in PSMB8 or PBK expression using the Student's $t$-test, the $\chi^{2}$ test, or Fisher's exact test. The relationships between expression of PSMB8 and PBK were assessed with a Spearman rank correlation coefficient. Cumulative survival plots were obtained using the Kaplan-Meier method, and significance was compared using the log-rank test. Statistical significance was set at $P$ $<0.05$. Multivariate analyses were carried out using Cox proportional hazards regression. Statistical calculations were performed using SSPS version 10.0 for Windows (SPSS Inc.; Chicago, IL, USA).

\section{ACKNOWLEDGMENTS}

The biospecimens for this study were provided by the Biobank of Pusan National University Hospital and
Chonnam National University Hwasun Hospital, members of the Korea Biobank Network. This study was supported by a grant (0920050) from the National R\&D Program for Cancer Control, Ministry for Health, Welfare and Family Affairs, Republic of Korea.

\section{CONFLICTS OF INTEREST}

No potential conflicts of interest were disclosed.

\section{REFERENCES}

1. Parkin DM, Bray F, Ferlay J, Pisani P. Global cancer statistics, 2002. CA Cancer J Clin 2005; 55:74-108.

2. De Vita F, Giuliani F, Galizia G, Belli C, Aurilio G, Santabarbara G, Ciardiello F, Catalano G, Orditura M. Neoadjuvant and adjuvant chemotherapy of gastric cancer. Ann Oncol 2007; 18 (suppl 6):vi120-3.

3. Zhang XF, Huang CM, Lu HS, Wu XY, Wang C, Guang GX, Zhang JZ, Zheng CH. Surgical treatment and prognosis of gastric cancer in 2,613 patients. World J Gstroenterol 2004; 10:3405-8.

4. Cui J, Li F, Wang G, Fang X, Puett JD, Xu Y. Geneexpression signatures can distinguish gastric cancer grades and stages. PLoS One. 2011; 6:e17819.

5. Cho JY, Lim JY, Cheong JH, Park YY, Yoon SL, Kim SM, Kim SB, Kim H, Hong SW, Park YN, Noh SH, Park ES, Chu IS, Hong WK, Ajani JA, Lee JS. Gene expression signature-based prognostic risk score in gastric cancer. Clin Cancer Res. 2011; 17:1850-7.

6. Zhang Y, Zhang L, Gao Y, Li C, Jia S, Liu N, Chen F, Niu D, Cho WC, Ji J, Zeng C. Discovery and validation of prognostric markers in gastric cancer by genome- wide expression profiling. World J Gastroenterol 2011; 17:171017.

7. Shin NR, Jeong EH, Choi CI, Moon HJ, Kwon CH, Chu IS, Kim GH, Jeon TY, Kim DH, Lee JH, Park do Y. Overexpression of Snail is associated with lymph node metastasis and poor prognosis in patients with gastric cancer. BMC Cancer 2012; 12:521.

8. Kwon CH, Park HJ, Lee JR, Kim HK, Jeon TY, Jo HJ, Kim DH, Kim GH, Park DY. Serpin peptidase inhibitor clade A member 1 is a biomarker of poor prognosis in gastric cancer. Br J Cancer. 2014; 111:1993-2002.

9. Lai MD, Xu J. Ribosomal proteins and colorectal cancer. Curr Genomics 2007; 8:43-49.

10. Caraglia M, Budillon A, Vitale G, Lupoli G, Tagliaferro P, Abruzzese A. Modulation of molecular mechanisms involved in protein synthesis machinery as a new tool for control of cell proliferation. Eur J Biochem 2000; 267:391936.

11. Byun HO, Han NK, Lee HJ, Kim KB, Ko YG, Yoon G, Lee YS, Hong SI, Lee JS. Cathepsin D and eukaryotic translation elongation factor 1 as promising markers of 
cellular senescence. Cancer Res 2009; 69:4638-47.

12. Domínguez-Sánchez MS, Sáez C, Japón MA, Aguilera A, Luna R. Differential expression of THOC1 and ALY mRNP biogenesis/export factors in human cancers. BMC cancer 2011; 11:77.

13. Ma YL, Peng JY, Zhang P, Huang L, Liu WJ, Shen TY, Chen HQ, Zhou YK, Zhang M, Chu ZX, Qin HL. Heterogeneous nuclear ribonucleoprotein A1 is identified as a potential biomarker for colorectal cancer based on differential proteomics technology. J Proteome Res 2009; $8: 4525-35$.

14. Schvartzman JM, Sotillo R, Benezra R. Mitotic chromosomal instability and cancer: Mouse modelling of the human disease. Nat Rev Cancer 2010; 10:102-115.

15. Bhui-Kaur A, Therwath A, Henry L, Chiesa J, Kurkure A, Scherrer K, Bureau JP. Increased prosomal proteins in breast cancer cells and in neighboring normal cells in Parsi and non-Parsi populations. J Cancer Res Clin Oncol 1998; 124:117-26

16. Tanaka F, Matsuzaki S, Mimori K, Kita Y, Inoue H, Mori M. Clinicopathological and biological significance of CDC28 protein kinase regulatory subunit 2 overexpression in human gastric cancer. Int J Oncol 2011; 39:361-72.

17. Shih MC, Chen JY, Wu YC, Jan YH, Yang BM, Lu PJ, Cheng HC, Huang MS, Yang CJ, Hsiao M, Lai JM. TOPK/ PBK promotes cell migration via modulation of the PI3K/ PTEN/AKT pathway and is associated with poor prognosis in lung cancer. Oncogene 2012; 31:2389-2400.

18. Cho JY, Lim JY, Cheong JH, Park YY, Yoon SL, Kim SM, Kim SB, Kim H, Hong SW, Park YN, Noh SH, Park ES, Chu IS, Hong WK, Ajani JA, Lee JS. Gene expression signature-based prognostic risk score in gastric cancer. Clin Cancer Res 2011; 17;1850-7.

19. D'Errico M, de Rinaldia E, Blasi MF, Viti V, Falchetti M, Calcagnile A, Sera F, Saieva C, Ottini L, Palli D, Palombo F, Giuliani A, Dogliotti E. Genome-wide expression profile of sporadic gastric cancers with microsatellite instability. Eur J Cancer 2009; 45;461-9.

20. Nettl PA, Berk DA, Swatz MA, Grodzinsky AJ, Jain RK. Role of extracellular matrix assembly in interstitial transport in solid tumors. Cancer Res. 2000; 60:2497-2503.

21. Brown EB, Boucher Y, Nasser S, Jaln RK. Measurement of macromolecular diffusion coefficients in human tumors. Microvasc Res. 2004; 67:231-6.

22. Belin S, Beghin A, Solano-Gonzalez E, Bezin L, BrunetManquat S, Textoris J, Prats A, Mertani H, Dumontet C, Diaz J. Dysregulation of ribosome biogenesis and translational capacity is associated with tumor progression of human breast cancer cells. PLoS One 2009; 4: e7147.

23. Silvera D, Formenti SC, Schneider RJ. Translational control in cancer. Nat Rev Cancer 2010; 10: 254-266.

24. Lamberti A, Caraglia M, Longo O, Marra M, Abbruzzese A, Arcari P. The translation elongation factor $1 \mathrm{~A}$ in tumorigenesis, signal transduction and apoptosis: review article. Amino Acids 2004; 26:443-8.

25. Mémin E1, Hoque M, Jain MR, Heller DS, Li H, Cracchiolo B, Hanauske-Abel HM, Pe'ery T, Mathews MB. Blocking eIF5A modification in cervical cancer cells alters the expression of cancer-related genes and suppresses cell proliferation. Cancer Res 2014; 74:552-62.

26. Pino I, Pio R, Toledo G, Zabalegui N, Vicent S, Rey N, Lozano D, Torre W, Montuenga LM. Altered patterns of expression of members of the heterogeneous nuclear ribonucleoprotein (hnRNP) family in lung cancer. Lung Cancer 2003; 41:131-43.

27. Li S, Xu H, Ding H, Huang Y, Cao X, Yang G, Li J, Xie Z, Meng Y, Li X, Zhao Q, Shen B, Shao N. Identification of an aptamer targeting hnRNP A1 by tissue slidebased SELEX. J Pathol 2009; 218:327-36.

28. Fukukawa C, Ueda K, Nishidate T, Katagiri T, Nakamura Y. Critical roles of LGN/GPSM2 phosphorylation by PBK/TOPK in cell division of breast cancer cells. Genes Chromosomes Cancer 2010; 49(10):861-872.

29. Wang JJ, Gang ZX, Ye HM, You P, Cai MJ, Daun HB, Wang F, Zhang ZY. Clinical significance of overexpressed cyclin-dependent kinase subunits 1 and 2 in esophageal carcinoma. Dis Esophaqus 2013; 26:729-36.

30. Shen DY, Zhan YH, Wang QM, Rui G, Zhang ZM. Oncogenic poteintial of cyclin kinase subunit-2 in cholagiocarcinoma. Liver Int 2013; 33:137-48.

31. Chen L, Madura K. Increased proteasome activity, ubiquitin-conjugating enzymes, and eEF1A translation factor detected in breast cancer tissue. Cancer Res 2005; 65:5599-5606.

32. Bazzaro M, Lee MK, Zoso A, Stirling WL, Santillan A, Shih IM, Roden RB.Ubiqutin-proteasome system stress sensitizes ovarian cancer to proteasome inhibitor-induced apoptosis. Cancer Res 2006; 66:3754-3763.

33. Dimmeler S, Breitschopf K, Haendeler J, Zeiher AM. Dephosphorylation targets Bcl-2 for ubiquitin-dependent degradation: a link between the apoptosome and the proteasome pathway. J Exp Med 1999; 189:1815-22.

34. Kumatori A, Tanaka K, Inamura N, Sone S, Ogura $\mathrm{T}$, Matsumoto $\mathrm{T}$, Tachikawa $\mathrm{T}$, Shin S, Ichihara A. Abnormally high expression of proteasomes in human leukemic cells. Proc Natl Acad Sci U S A 1990; 87:7071-5.

35. Kanayama H, Tanaka K, Aki M, Kagawa S, Miyaji H, Satoh M, Okada F, Sato S, Shimbara N, Ichihara A. Changes in expressions of proteasome and ubiquitin genes in human renal cancer cells. Cancer Res 1991; 51:6677-85

36. Ayllon V, O'Connor R. PBK/TOPK promotes tumour cell proliferation through $\mathrm{p} 38$ MAPK activity and regulation of the DNA damage response. Oncogene 2007; 26:3451-61.

37. Hu F, Gartenhaus RB, Eichberg D, Liu Z, Fang HB, Rapoport AP. PBK/TOPK interacts with the DBD domain of tumor suppressor p53 and modulates expression of transcriptional targets including p21. Oncogene 2010; 29:5464-74. 
38. Zhu F, Zykova TA, Kang BS, Wang Z, Ebeling MC, Abe Y, Ma WY, Bode AM, Dong Z. Bidirectional signals transduced by TOPK-ERK interaction increase tumorigenesis of HCT116 colorectal cancer cells. Gastroenterology 2007; 133:219-31.

39. Zykova TA, Zhu F, Lu C, Higgins L, Tatsumi Y, Abe Y, Bode AM, Dong Z. Lymphokine-activated killer T-celloriginated protein kinase phosphorylation of histone H2AX prevents arsenite-induced apoptosis in RPMI7951 melanoma cells. Clin Cancer Res 2006; 12:6884-93.

40. Keely PJ, Westwick JK, Whitehead IP, Der CJ, Parise LV. Cdc42 and Rac1 induce integrin-mediated cell motility and invasiveness through PI(3)K. Nature 1997; 390: 632-66.

41. Dhillon AS, Hagan S, Rath O, Kolch W. MAP kinase signaling pathway in cancer. Oncogene 2007; 26:32793290.
42. Geng F, Wenzel S, Tanswy WP. Ubiquitin and proteasomes in transcription. Annu Rev Biochem 2012; 81:177-201.

43. O'Hara A, Howarth A, Varro A, Dimaline R. The role of proteasome beta subunits in gastrin-mediated transcription of plasminogen activator inhibitor-2 and regenerating protein1. Plos one 2013; 8:e59913.

44. Park JH, Lin ML, Nishidate T, Nakamura Y, Katagiri T. PSZ-binding kinase/T-LAK cell-originated protein kinase, a putative cancer/testis antigen with an oncogenic activity in breast cancer. Cancer Res. 2006; 66:9186-9195.

45. Lei B, Qi W, Zhao Y, Li Y, Liu S, Xu X, Zhi C, Wan L, Shen H. PBK/TOPK expression correlates with mutant p53 and affects patients' prognosis and cell proliferation and viability in lung adenocarcinoma. Hum Pathol 2015; 46:217-24. 